\title{
Grey Forecasting Model for Taiwan's Machine Tool Export Value
}

\author{
Ching-I LIN \\ Department of Industrial Management, \\ Lunghwa University of Science \& Technology \\ Taoyuan, Taiwan \\ E-mail: ljybibi2307@gmail.com
}

\author{
Kuo-An TSENG* \\ Department of Finance, \\ Lunghwa University of Science \& Technology \\ Taoyuan, Taiwan \\ E-mail: andy@mail.lhu.edu.tw \\ +* Corresponding author
}

\author{
Shih-Hung TAI \\ Department of Industrial Management, \\ Lunghwa University of Science \& Technology \\ Taoyuan, Taiwan \\ E-mail: tai3662@mail.lhu.edu.tw
}

\begin{abstract}
Machine tools facilitate the production of other industrial equipment and machinery - they are the opening point of almost every metal manufacturing activity. Taiwan has built up machine tool industry over a period of times. Our primary aim is to predict the future values for the export value of Taiwan's machine tool and to provide the reference for its developing tendency. Grey forecasting model has been broadly applied in numerous research fields and has achieved superior prediction accuracy. The article applies the grey forecasting model to forecast the export value of Taiwan machine tool. To measure the performance of the GM $(1,1)$ model, the criteria of MAPE is adopted. Empirical results indicate that the GM (1, 1) forecasting model has the MAPE, $4.52 \%$, so the forecasting power of expression is high. That is, GM $(1,1)$ forecasting model has a high prediction validity of forecasting the export value of Taiwan machine tool. The establishment of the prediction model for Taiwan's machine tool export value hopes the Government and industry can, through predictable results, advance understanding of market trends and prepared countermeasures. The results should provide valuable information for dealing with similar managerial issues.
\end{abstract}

Keywords-forecasting; grey theory; machine tool

\section{INTRODUCTION}

The machine tool industry is located at the beginning of the industrial supply chain, machine tools facilitate the production of other industrial equipment and machinery they are the opening point of almost every metal manufacturing activity. Needless to say that machine tool has a essential impact on the productivity and competitiveness of the manufacturing industry.

Taiwan has built up machine tool industry over a period of times. Taiwan is one of the world's largest machinery exporters. More than $60 \%$ of the production was exported. Long-term investment by Taiwanese firms in the development of key machine tool parts and components have successfully boosted the industry's performance and technological expertise. Further, local manufacturers have been successful in developing international markets.

Taiwan Association of Machinery Industry reported that Taiwan machine tool output value of 2014 is 3.75 billion US dollars, gaining ground on Italian exports ranked fourth in the world, ahead of China and South Korea the top three producers in turn is Germany, Japan (15.8\%) and Italy $(6.2 \%)[1]$.

It is worth mentioning that the Taiwan have caught up with Italy (Taiwan exports \$ 3.75 billion, Italy $\$ 3.83$ billion), while China is in hot pursuit after Taiwan.

Faced with the arrival of Industry 4.0, there is great development space for Taiwan machine tool industry, Taiwan's products compete against Japanese and German technology at the higher price levels, and face low price competition from China at the lower end of the market. Government and machine tool industry should predict the future export markets. The purpose of this research is to establish the prediction model for Taiwan's machine tool export value, hope the Government and industry can, through predictable results, advance understanding of market trends and prepared countermeasures.

Accordingly, one of main concerns in this article is to construct forecasting model to forecast the export value of Taiwan machine tool. Deng proposed gray system theory in 1982, as the system model of unclear and incomplete information to build a grey model for prediction and decision-making [2]. Besides, the grey forecasting model (GM) is the core of grey system theory and the GM $(1,1)$ is one of the most commonly used grey forecasting model. Over the past few years, it has been broadly applied in numerous research fields and has achieved superior prediction accuracy [3-6]. So, we choose the grey prediction GM $(1,1)$ model to predict the future values for the export value of Taiwan machine tool and to provide the reference for its developing tendency. 


\section{Methodology}

The basic idea of $\operatorname{GM}(1,1)$ model is to make original series accumulate and generate new series, weaken the randomness of the original series, reveal its regularity, make the new sequence reflecting the trend of the original series, to achieve the orderly sequence analysis, and meet the requirements of forecasting.

\section{A. Steps of Grey Model GM $(1,1)$}

The GM $(1,1)$ model constructing process is described as follows:

Step 1: Denote the original data sequence.

$$
x^{(0)}=\left(x^{(0)}(1), x^{(0)}(2), x^{(0)}(3), \ldots, x^{(0)}(n)\right), \quad n \geq 4
$$

Step 2: Use AGO (accumulated generating operations) to form a new data series.

$$
x^{(1)}=\left(x^{(1)}(1), x^{(1)}(2), x^{(1)}(3), \ldots, x^{(1)}(n)\right),
$$

where $x^{(1)}(1)=x^{(0)}(1)$ and

$$
x^{(1)}(k)=\sum_{i=1}^{k} x^{(0)}(i), \quad k=2,3, \ldots, n
$$

Step 3: Calculate background values $Z^{(1)}$

$$
z^{(1)}(k)=(1-\alpha) x^{(1)}(k-1)+\alpha x^{(1)}(k), \quad \alpha \in(0,1)
$$

Step 4: Establish the grey differential equation.

$$
\frac{d x^{(1)}(k)}{d t}+a x^{(1)}(k)=b
$$

where $a$ is the developing coefficient and $b$ is the grey input.

Step 5: Solve Eq.(4) by using the least square method and the forecasting values can be obtained as

$$
\left\{\begin{array}{l}
\hat{x}^{(1)}(k)=\left(x^{(0)}(1)-\frac{b}{a}\right) e^{-a(k-1)}+\frac{b}{a} \\
\hat{x}^{(0)}(k)=\hat{x}^{(1)}(k)-\hat{x}^{(1)}(k-1)
\end{array}\right.
$$

where,

$$
\begin{gathered}
{[a, b]^{T}=\left(B^{T} B\right)^{-1} B^{T} Y} \\
Y=\left[x^{(0)}(2), x^{(0)}(3), \ldots, x^{(0)}(n)\right]^{T}
\end{gathered}
$$

$$
B=\left[\begin{array}{cc}
-z^{(1)}(2) & 1 \\
-z^{(1)}(3) & 1 \\
\vdots & \vdots \\
-Z^{(1)}(n) & 1
\end{array}\right]
$$

\section{B. The Applied Range of $G M(1,1)$ Model}

In order to calculate forecasting accuracy, the estimated results are evaluated by Mean Absolute Percentage Error (MAPE). The MAPE is a measure of prediction accuracy of a forecasting method in statistics. It usually expresses accuracy as a percentage, and is defined by the formula:

$$
M A P E=\frac{1}{n} \sum_{i=1}^{n}\left|\left(P_{i}-A_{i}\right) / A_{i}\right|
$$

where $A_{i}$ is the actual value and $P i$ is the forecast value.

The difference between $\mathrm{A}_{\mathrm{i}}$ and $\mathrm{P}_{\mathrm{i}}$ is divided by the Actual value $A_{i}$ again. The absolute value in this calculation is summed for every forecasted point in time and divided by the number of fitted points n. Multiplying by 100 makes it a percentage error. Deng [7] has offered a criterion such as table I for MAPE:

TABLE I. MAPE FOR MODEL EVALUATION

\begin{tabular}{|c|c|}
\hline MAPE (\%) & Forecasting Power \\
\hline$>50$ & Weak and inaccurate forecasting \\
\hline $20-50$ & Reasonable forecasting \\
\hline $10-20$ & Good forecasting \\
\hline$<10$ & Highly accurate forecasting \\
\hline
\end{tabular}

Source: Deng [7].

\section{EMPIRICAL STUDIES}

To demonstrate the precision and stability of grey forecasting method, the export Value of Taiwan Machine Tool provided by TAMI are examined in this study. The historical annual data of Export value of Taiwan machine tool from 2011 to 2015 are presented in Table II.

TABLE II. EXPORT VALUE OF TAIWAN MACHINE TOOL

\begin{tabular}{ccc} 
& & Unit: US\$ Million \\
\hline Year & accounting & \\
2011 & 4,001 \\
2013 & 4,236 \\
2014 & 3,548 \\
2015 & 3,753 \\
\hline
\end{tabular}

\section{A. Formulating the GM(1,1) Models}

The original data sequence is obtained as $x(0)=(4001,4236,3548,3753,3184)$ based on the export Value of Taiwan machine tool from 2011 to 2015. The parameters 
of $a$ and $b$ of original GM $(1,1)$ model are estimated by the least-square method through the Eqs. (2)-(4). $(a=0.0807$, $\mathrm{b}=4626.3269)$. The original GM $(1,1)$ forecasting model is listed as follow:

$$
\begin{gathered}
x(0)=(4001,4236,3548,3753,3184) \\
a=0.0807, b=4626.3269
\end{gathered}
$$

\section{B. Results}

The predicted results obtained by the original $\operatorname{GM}(1,1)$ are presented in Table III To measure the forecasting performance, mean absolute percentage error (MAPE), is used for evaluation of GM(1,1) model. The MAPE is $4.52 \%$ (less than 10\%); so the forecasting power of expression is high.

TABLE III. FORECASTING VALUES AND ERRORS OF EXPORT VALUE OF TAIWAN MACHINE TOOL

\begin{tabular}{c|c|c|c}
\hline \multicolumn{2}{|c}{ Year } & ${ }^{a} A_{i}$ & \multicolumn{2}{c}{ Unit: US\$ Million } \\
\cline { 3 - 4 } & & ${ }^{b} P_{i}$ & ${ }^{c}$ Error(\%) \\
\hline 2011 & 4,001 & & \\
2012 & 4,236 & 4,135 & $2.39 \%$ \\
2013 & 3,548 & 3,814 & $7.50 \%$ \\
2014 & 3,753 & 3,519 & $6.24 \%$ \\
2015 & 3,184 & 3,246 & $1.95 \%$ \\
MAPE & & & $4.52 \%$ \\
\hline \multicolumn{2}{r}{} \\
\end{tabular}

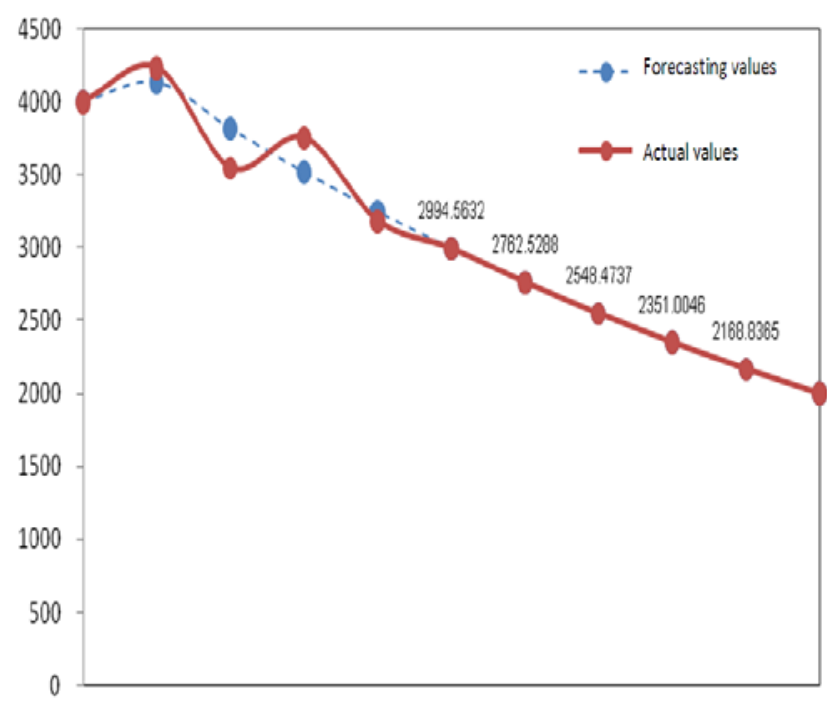

Figure 1. Actual values and forecasting values.

\section{CONCLUSIONS}

Accordingly, the goal of this article is to forecast the export value of Taiwan machine tool by original GM $(1,1)$ model. To measure the performance of the GM $(1,1)$ model, the criteria of MAPE is adopted. Empirical results indicate that the GM $(1,1)$ forecasting model has the MAPE, $4.52 \%$, so the forecasting power of expression is high. That is, GM $(1,1)$ forecasting model has a high prediction validity of forecasting the export value of Taiwan machine tool.

However, the trend of export value of Taiwan machine tool seems to be decrease. Taiwan's products compete against Japanese and German technology at the higher price levels, and face low price competition from China at the lower end of the market. In response to these challenges, local machine tool firms should continually evaluate market needs, use product differentiation strategies and develop products that fit market niches. The government should large-scale support of the sector along with the steady effort of companies to help domestic machinery industry to accumulate notable capabilities in $\mathrm{R} \& \mathrm{D}$, manufacturing and marketing.

The market potential in emerging markets such as Brazil, India, Turkey, Russia, ASEAN (Association of Southeast Asian Nations), and the Middle East offers interesting business opportunities for Taiwanese machinery manufacturers with good quality machines at reasonable prices. With the steadily increasing business in emerging markets, TAMI noted that local machinery suppliers are set to play an even more important role in these markets.

\section{ACKNOWLEDGMENT}

Thanks to Taiwan Association of Machinery Industry to provide the important data, as well as providing industry advice for the research, making this research more realistic and can be successfully completed.

\section{REFERENCES}

[1] Taiwan Association of Machinery Industry (2015), http://www.tami.org/st/taiwan_ind_201512

[2] Deng, J. L. Grey system fundamental method. Huazhong University of Science and Technology, Wuhan, China. (1982).

[3] Kayacan, E., Ulutas, B., \& Kaynak, O. Grey system theory-based models in time series prediction. Expert systems with applications, (2010), p.37, p.1784-1789.

[4] Shen, V. R. L., Chung, Y. F., \& Chen, T.S. A novel application and grey system theory to information security (part I). Computer standards and interfaces, (2009), p.31, p.277-281.

[5] Li, G., Wang, T. (2011). A new model for information fusion based on grey theory. Inform. Technol. J, 10, 189-194.

[6] Truong, D.Q. and Ahn, K.K. (2012), "Wave prediction based on a modified grey model MGM $(1,1)$ for real-time control of wave energy converters in irregular waves”, Renewable Energy, Vol. 43, pp. 242-255.

[7] Deng, J. L. Grey prediction and decision. Huazhong University of Science and Technology, Wuhan, China.(1986). 